\title{
Study of thyroid volume by ultrasonography in clinically euthyroid patients
}

\author{
P. Kayastha, S. Paudel, D. M. Shrestha, R. K. Ghimire, S. Pradhan \\ Department of Radiology and Imaging, Institute of Medicine, Tribhuvan University Teaching Hospital, Kathmandu, Nepal \\ Correspondence to: P. Kayastha, Department of Radiology and Imaging, Tribhuvan University Teaching Hospital, \\ Kathmandu, Nepal \\ Email:dr_prakash_kayastha@hotmail.com
}

\begin{abstract}
Introduction: The purpose of this study was to establish reference ranges of total thyroid volume among clinically euthyroid Nepalese population using Ultrasonography and correlate this volume with age, sex, individual's built and geographic location.

Methods: This was a prospective cross sectional study involving 485 clinically euthyroid individuals. B - mode Ultrasonography was used to measure the total thyroid volume by combining the volume of both the lobes obtained by using formula for prolate ellipsoid. Age specific reference values for thyroid volume were obtained and Pearson correlation test was used to see the relationship with various factors.
\end{abstract}

Results: Among 485 individuals between 1 to 83 years of age, 221(45.57\%) were males and 264(54.43\%) were females. Maximum [354 individuals (72.99\%)] were from hilly region and minimum [16 individual $(3.30 \%)$ ] were from Himalayan region. Mean thyroid volume was $6.629 \pm 2.5025 \mathrm{ml}$. In general, thyroid volume was found to be more in older individuals than in young age group. There was no significant difference of thyroid volume between males and females. Thyroid volume best correlated with body surface area $(r=0.444, p<0.0001)$. The volume had a positive correlation with weight $(r=0.443, p<0.0001)$, body mass index $(r=0.371, \mathrm{p}<0.0001)$ and height $(\mathrm{r}=0.320, \mathrm{p}<0.0001)$ of the individual.

Conclusions: This study estimated the reference range of total thyroid volume for Nepalese population. These ranges are significantly lower than the WHO/ICCIDD thyroid volume references and reference values obtained in various other countries. Total thyroid volume best correlated with Body surface area.

Keywords: Body surface area, clinically euthyroid, total thyroid volume, ultrasonography

\section{Introduction}

Thyroid is a vital endocrine gland of our body which is located superficially in the infrahyoid compartment of neck in a space outlined by muscle, trachea, esophagus, carotid arteries and jugular veins. It lies against C5 to T1 vertebral level. ${ }^{1}$ It is involved in the production, storage and release of thyroid hormones thyroxine (T4) and triiodothyronine (T3). Thyroid hormones are required for various physiological actions in the body including regulation of body metabolism. They are the essential hormones for the growth and development of the individual.

The size and shape of the gland varies widely in normal individuals. Normally in tall individuals, the lobes have an elongated shape where as in shorter individuals they are oval. As a result, the normal dimensions of the gland have wide variability. ${ }^{1}$ Besides a number of physiological and pathological factors affect thyroid volume. Many factors influence the size of the thyroid gland, among which age, sex, body mass index, body surface area, iodine etc. are of 
importance. These factors seem to interact in a complex way. ${ }^{2}$ A profound negative relationship between increasing iodine intake and goiter prevalence is incontestable., ${ }^{2,3}$

Estimation of the thyroid volume is generally considered to be important in several pathologic situations such as iodine deficiency goiter, thyroiditis, multinodular goiter, and others. For example, it allows evaluation of the efficacy of suppressive levothyroxine therapy in thyrotoxicosis during their follow-up. Quite recently in addition, it increases interest because of the introduction of minimally invasive surgery that requires the most correct evaluation of the mass of the gland on which to operate. Indeed, the main limiting factor when selecting patients for minimally invasive procedures is the gland mass, which should not exceed 20 ml volume. ${ }^{4,5}$

There are various methods of estimating thyroid size and volume like palpation, ultrasonography, radionuclide study, computed tomography etc. As this gland is located superficially, it can be easily palpated. There is disagreement about which system of palpation best describes the size of the thyroid gland: one based on estimated weight or one based on other variables, such as the presence of a visible prominence. The paucity of data comparing different methods of thyroid examination or size determination makes it difficult to recommend the use of one method over another. ${ }^{6,7}$

It has been suggested that the ultrasonographic estimation of thyroid volume would overcome the problems of overestimation of goiter prevalence and marked interobserver variability associated with palpation estimates. ${ }^{8}$ Thyroid ultrasonography has proven a useful and practical method for the assessment of thyroid size. ${ }^{9-11}$ The availability of portable ultrasound equipment has facilitated its application to epidemiological studies. ${ }^{12-14}$ Apart from measurement of the thyroid size, ultrasound can detect non palpable nodules, estimate the size of the nodule and characterize the nodule.

In many of the western as well as our neighbouring countries, sonographic study has been done to assess the thyroid volume in children and adults. Various investigators have measured thyroid volume and have found different values for normal euthyroid patients. Hegedus L, et al. in a study showed that in adult, the mean thyroid volume is $18.6+/-$ $4.5 \mathrm{ml}(\mathrm{M}=19.6+/-4.7 \mathrm{ml}, \mathrm{F}=17.5+/-4.3 \mathrm{ml}) .{ }^{10}$ This converts to $18.6 \mathrm{gm}$. Similarly Ivanac $\mathrm{G}$ et al found mean thyroid volume of $10.68+/-2.83 \mathrm{ml}$ (range $5.71-17.09 \mathrm{ml}){ }^{15}$

In Nepalese population, the volume of the gland has not been established till date. The reference of the thyroid volume in our population is still based on western data.
Before applying size criteria to diagnose the goitre, we have to establish the normal range of size of the gland in relation to age, sex, weight, height and geographical region where one resides as it is a known fact that thyroid volume is greatly influenced by these factors.

So this study was done in an attempt to establish the thyroid volume in normal Nepalese population in relation to age, sex, weight, height, body surface area, body mass index and geographic region.

\section{Methods}

This was a prospective cross sectional study involving 485 cases without any known thyroid disease or symptoms related to thyroid disease. The study was conducted in the Department of Radiology and Imaging, Tribhuvan University Teaching Hospital (TUTH) from September 2007 to August 2008.

Persons without signs and symptoms of thyroid disease irrespective of the age and sex who presented in the various departments of TUTH were included in the study. Patients with known thyroid disease, presence of thyroid nodule causing enlargement of thyroid gland, heterogeneous echotexture of thyroid gland and increased vascularity of the gland were excluded from the study.

Patient who came for Ultrasonography examination, for various reasons other than thyroid problems, were included in the study after obtaining informed consent. Detail information was recorded in the pre designed data collection sheet. Information included were particulars of the patients, history regarding thyroid symptoms, demographic location of the individual. Demographic location was assigned as per the division of country into Himalayan region, hilly region and Terai region. Patients' height in meters and weight in kilograms were recorded.

Body mass index (BMI) of the patient was obtained by using the formula:

$\mathrm{BMI}=$ weight in $\mathrm{Kg} /(\text { height in } \mathrm{m})^{2}$

Body surface area (BSA) was obtained by using Mosteller formula:

$\operatorname{BSA}\left(\mathrm{m}^{2}\right)=$ “ (height in $\mathrm{cm} \mathrm{x}$ weight in $\left.\mathrm{kg}\right) / 3600$

All the individuals were examined in the supine position with the neck hyperextended. Using a linear 7.5 MHz probe in SONOACE 8000 LIVE machine, transverse and longitudinal sections of both lobes of the thyroid gland were scanned. Measurements of the maximum length of the lobe from the sagittal images were recorded. The maximum transverse diameter (breadth) and the maximum depth of 
each lobe were recorded from the transverse images. To ensure that the probe was in the same position each time, anatomical landmarks were used. For measurement of thyroid length, the probe was placed longitudinally in the midline of the neck to obtain sagittal views of the larynx; the probe was then moved obliquely to find the maximum length of the thyroid gland, just medial to the carotid vessels. The transverse views were obtained by using the trachea and carotid vessels as landmarks (Fig.1\& 2).

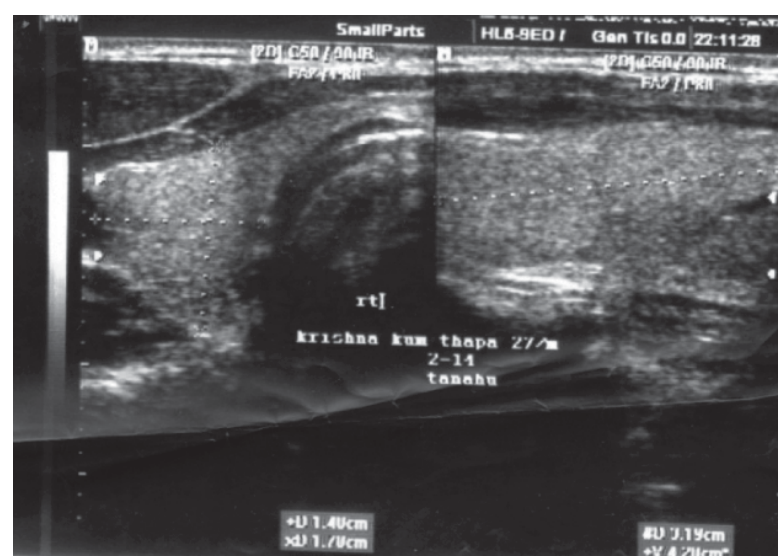

Fig. 1: Measurement of volume of right lobe of thyroid gland.

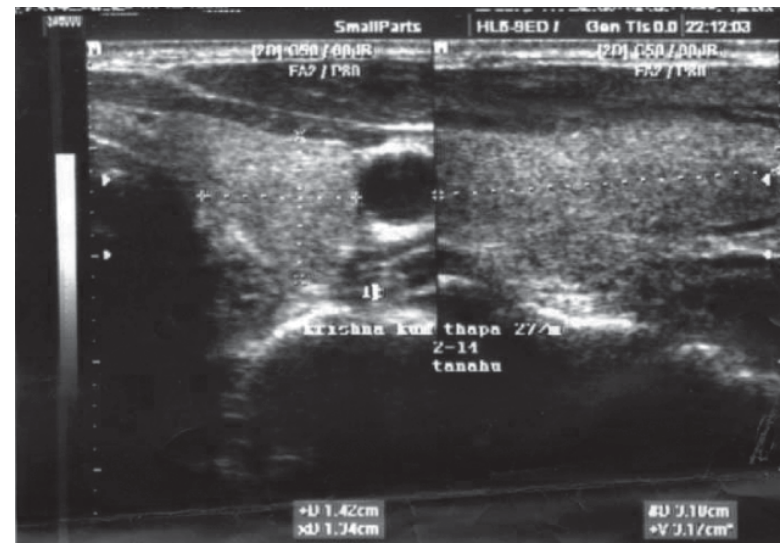

Fig. 2: Measurement of volume of left lobe of thyroid gland

The volume of each lobe was calculated automatically by the machine using the formula for a prolate ellipsoid, where Thyroid volume $=$ length $\mathrm{x}$ breadth $\mathrm{x}$ depth $\mathrm{x} \circlearrowright / 6$.

Total thyroid volume was obtained by adding the volume of both the lobes. Volume of isthmus was not included in the total thyroid volume.

Data obtained were compiled and analyzed using standard statistical analysis. SPSS 11.5 and Microsoft Excel were utilized for the data analysis and presentation. Pierson correlation was used to see the relation of various demographic parameters with total thyroid volume. Independent t-test was used to calculate the significance between sex groups and different demographic groups. Paired t-test was used to compare the difference between the volumes of two lobes of the gland in the same individual.

\section{Results}

The thyroid gland volume was estimated in all 485 individuals. Characteristics of the study population are shown in figures 3, 4 and 5. Mean age was 34.06 years (range 1-83years). Maximum number of individuals (34.02\%) were in the age group of 20-29 years. Lowest number of individuals $(1.03 \%)$ were in the age group of above 80 years. Out of 485 individuals, 221 individuals $(45.57 \%)$ were males and 264 individuals (54.43\%) were females. Among all 16 individuals $(3.30 \%)$ were from Himalayan region, 354 individuals $(72.99 \%)$ were from hilly region and 115 individuals (23.71\%) were from Terai.

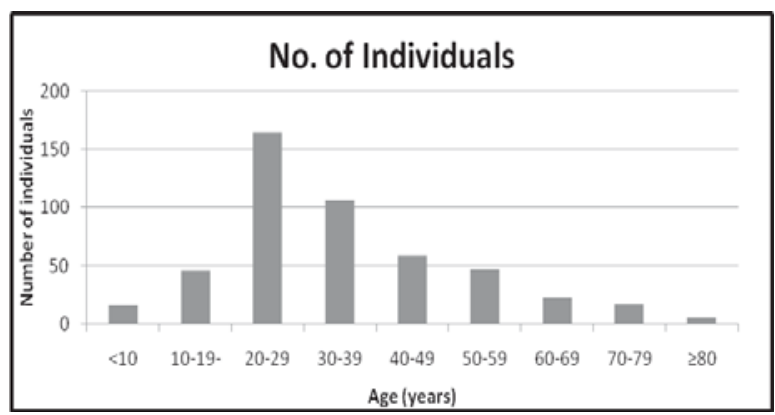

Fig. 3: Distribution of individuals by age

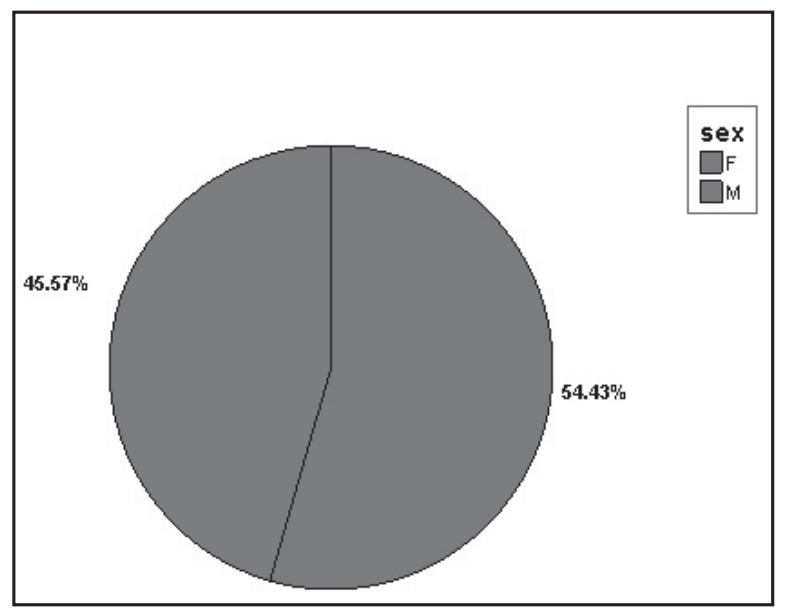

Fig. 4: Distribution of individuals by sex 


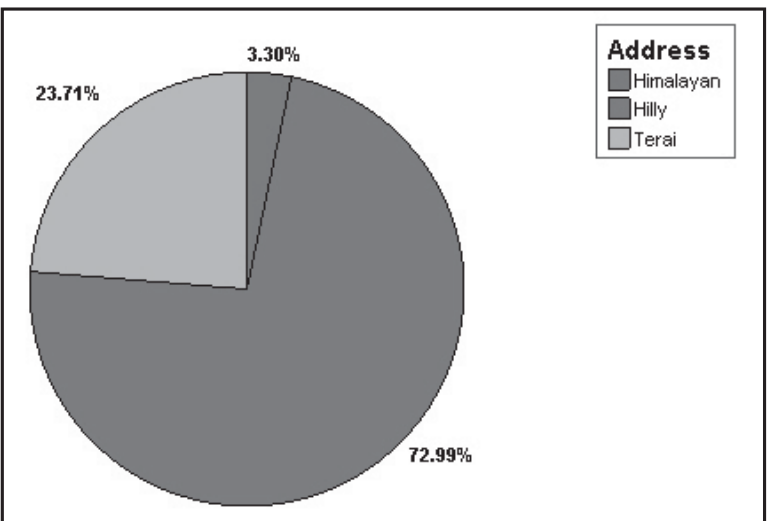

Fig. 5: Distribution of individuals by demographic location

\section{Thyroid volume:}

Calculated mean total thyroid volume was $6.629 \pm 2.5025 \mathrm{ml}$ $(=6.629 \pm 2.5025 \mathrm{~g})$. Right lobe volume was $3.7910 \pm 0.06647 \mathrm{ml}$ while that for left lobe was $2.8367 \pm 0.05435 \mathrm{ml}$. Right lobe had significantly higher volume than the left $(\mathrm{p}<0.0001)$. Maximum thyroid volume was $24.95 \mathrm{ml}$ and minimal volume was $1.59 \mathrm{ml}$.

Table 1: Volume of thyroid gland

$\begin{array}{lllll} & \mathbf{N} & \text { Mean } & \text { Std. Deviation Std. Error Mean } \\ \begin{array}{l}\text { Total volume } \\ \begin{array}{l}\text { Right lobe } \\ \text { volume }\end{array}\end{array} & 485 & 6.629 & 2.5025 & 0.1136 \\ \begin{array}{l}\text { Left lobe } \\ \text { volume }\end{array} & 485 & 3.7910 & 1.46374 & 0.06647 \\ & 4.8367 & 1.19699 & 0.05435\end{array}$

\section{Age specific reference values:}

The reference values of total thyroid volume for different ages are shown in Table 2. The total thyroid volume increased with increasing age of the patient upto 80 years $(\mathrm{r}$ $=0.292, \mathrm{p}<0.0001)$ with highest value of $8.504706 \pm 4.915199$ $\mathrm{ml}$ for the age group of 70 to 79 years.

Table 2: Age specific reference values for total thyroid volume.

\begin{tabular}{llll} 
Age (years) & Sample size (n) & \multicolumn{2}{c}{ Total thyroid volume $(\mathbf{m l})$} \\
& & Mean & Std. Deviation \\
$<10$ & $16(3.29 \%)$ & 1.785 & 0.769251 \\
$10-19$ & $46(9.69 \%)$ & 5.113043 & 1.78792 \\
$20-29$ & $165(34.02 \%)$ & 6.643636 & 1.87136 \\
$30-39$ & $107(22.06 \%)$ & 7.220093 & 2.108951 \\
$40-49$ & $59(12.16 \%)$ & 6.988644 & 2.16853 \\
$50-59$ & $47(9.69 \%)$ & 6.497872 & 1.705072 \\
$60-69$ & $23(4.74 \%)$ & 8.123043 & 4.185859 \\
$70-79$ & $17(3.50 \%)$ & 8.504706 & 4.915199 \\
e" 80 & $5(1.03 \%)$ & 6.644 & 1.989354
\end{tabular}

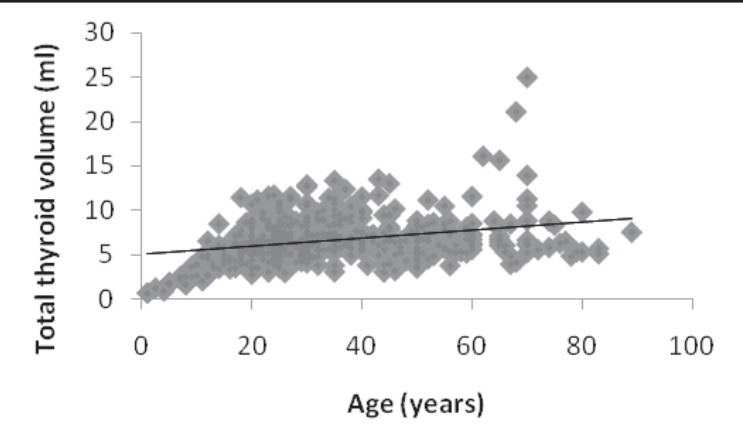

Fig. 6: Relationship of total thyroid volume with age

\section{Thyroid volume and Sex}

Total thyroid volumes for males and females were $6.849 \pm$ $2.7448 \mathrm{ml}$ and $6.444 \pm 2.2689 \mathrm{ml}$ respectively. The difference in values were not significant $(\mathrm{p}=0.076)$.

\section{Thyroid volume and demographic location}

Thyroid volume for individuals from Himalayan region was highest (mean $8.958 \pm 3.6314 \mathrm{ml}$ ) and it was lowest for those from Terai region (mean $6.364 \pm 1.9598 \mathrm{ml}$ ).

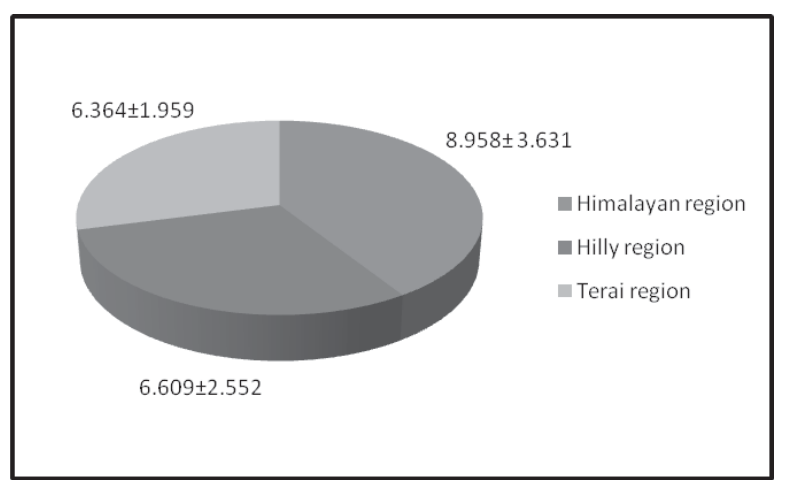

Fig. 7: Mean thyroid volume (ml) for different geographic locations 
Mean thyroid volume of individuals from Himalayan region was significantly higher than that from hilly and Terai region ( $p<0.0001)$. Difference of thyroid volume between individuals from hilly and Terai region was not significant $(\mathrm{p}=0.345)$.

\section{Thyroid volume and individuals built}

Total thyroid volume significantly correlated with individual's height, weight, body mass index and body surface area $(\mathrm{p}<0.0001)$. Highest correlation was found with body surface area $(\mathrm{r}=0.444)$.

Table 3: Correlation of total thyroid volume with various parameters

$\begin{array}{lll}\text { Parameter } & \text { Pearson correlation } & \text { pvalue } \\ \text { Weight } & 0.443 & 0.000 \\ \text { Height } & 0.320 & 0.000 \\ \text { BMI } & 0.371 & 0.000 \\ \text { BSA } & 0.444 & 0.000 \\ \text { Age } & 0.292 & 0.000\end{array}$

Total thyroid volume is increased with increasing body mass index (Fig. 8) and body surface area (Fig. 9).

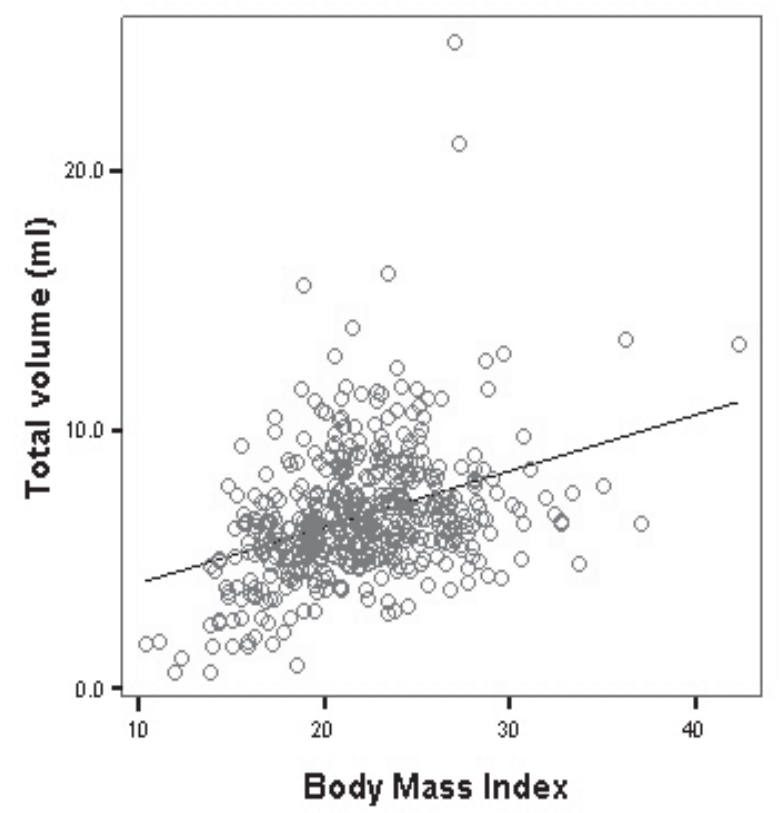

Fig. 8: Relation of total thyroid volume (ml) with Body Mass Index (BMI)

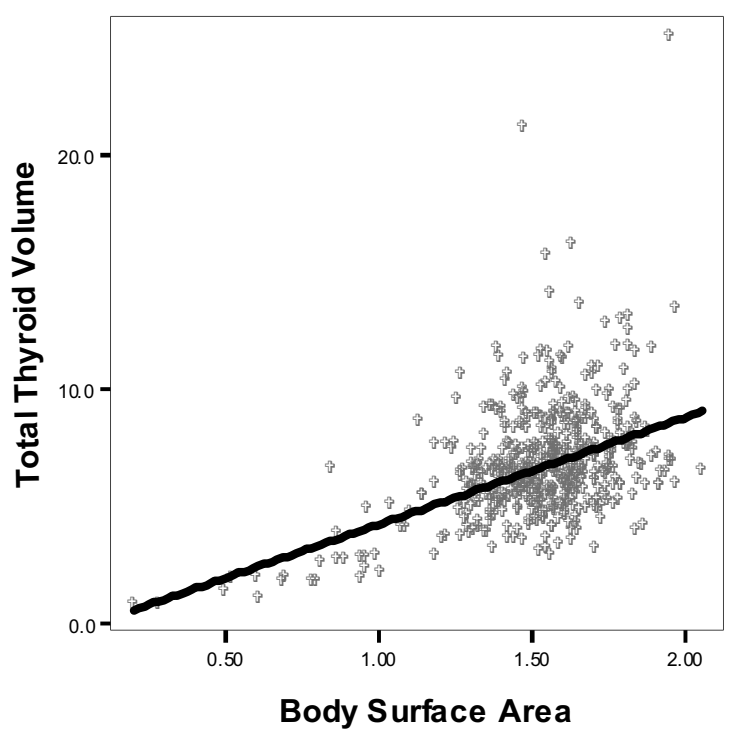

Fig. 9: Relation of total thyroid volume (ml) with Body Surface Area $\left(\mathrm{m}^{2}\right)$

\section{Discussion}

We estimated the reference values of total thyroid volume based on ultrasonographic measurements of thyroid gland for Nepalese population based on the cross sectional observations in total 485 individuals. Relation of total thyroid volume with age, sex, height, weight, body mass index, body surface area and geographic location of the individuals were studied.

\section{Total thyroid volume}

The study showed that the mean total thyroid volume was $6.629 \pm 2.5025 \mathrm{ml}$. This value is lower than that obtained by Hegedus $\mathrm{L}$ et $\mathrm{al}^{10}$, Chanoine $\mathrm{JP}$ et $\mathrm{al}^{16}$ and Ivanac $\mathrm{G}$ et al ${ }^{15}$. In the study done by Hegedus L et al mean thyroid volume was $18.6 \pm 4.5 \mathrm{ml}$. All the subjects in our study had thyroid volume lower than the mean thyroid volume obtained by Hegedus L et al. ${ }^{10}$ In the study carried out by Chanoine JP et al mean thyroid volume was $2.7(0.8)$ in prepubertal subjects aged 8-11 years and $11.6(4.4) \mathrm{ml}$ in late pubertal subjects aged greater than 17 years. ${ }^{16}$ Mean thyroid volume obtained by Ivanac $\mathrm{G}$ et al from 51 females aged 20 to 38 years (mean 22) was $10.68 \pm 2.83 \mathrm{ml}^{15}$ Increasing use of iodine supplimentation in our country in the recent years could be one of the factors reducing the iodine deficiency prevalent in the country and thus reducing the total thyroid volume. 
Considerable discrepancy exist between the size of right and left lobes of thyroid gland in individual. ${ }^{17}$ In our study, right lobe of the thyroid gland had significantly higher volume than the left lobe $(3.7910 \pm 0.06647 \mathrm{ml}$ vs $2.8367 \pm$ $0.05435 \mathrm{ml}$ ). No explanation was found for this difference.

\section{Age-specific thyroid volume}

We have calculated age specific thyroid volume. In general, thyroid volume increased with increasing age of the individual. This finding is similar to various other studies. ${ }^{16,18-20}$ In a study done by Chanoine JP et al in 256 euthyroid subjects aged 0 to 20 years total thyroid volume increased significantly $(\mathrm{p}<0.001)$ until the age of 8 years without influenced by sex and thereafter varied widely. ${ }^{16}$ Dvoráková $\mathrm{M}$ et al showed the age-related increase of the volume of thyroid gland at both sexes $(\mathrm{F}$-ratio $=1.99, \mathrm{p}<$ 0.0001). ${ }^{19}$ However, our age specific reference values are lower than the reference values obtained by various researchers. ${ }^{16,20}$ In the study carried out by Chanoine JP, et al mean thyroid volume was $2.7(0.8)$ in prepubertal subjects aged 8-11 years and $11.6(4.4) \mathrm{ml}$ in late pubertal subjects aged greater than 17 years. Our age specific reference values are also lower than WHO/ICCIDD thyroid volume references. ${ }^{21}$

\section{Thyroid volume and sex}

We didn't find any significant difference in total thyroid volume between males and females. Similar observations were made by $\mathrm{F} \mathrm{Xu}$ et al. ${ }^{22}$ A number of other studies based on ultrasonography in iodine sufficient areas have also found no difference by sex..$^{23-26}$ However, Hegedus L et al found a significant difference in volume between males (19.6 $\pm 4.7 \mathrm{ml})$ and females $(17.5 \pm 4.2 \mathrm{ml})$. The difference in thyroid gland volume between males and females was explained solely by a difference in body weight. ${ }^{10}$

\section{Thyroid volume and demographic location}

It is a well known fact that iodine deficiency is one of the major factors of enlargement of thyroid gland and dietary iodine is different in different geographic locations. In a geographic area where mild iodine deficiency is common, a significant relation between iodine intake and thyroid volume exists. Generally iodine content is lower in the high mountain regions. Himalayan region and hilly region of our country are such areas.

We found significantly higher thyroid volume in the Himalayan sample as compared to hilly and Terai samples. However, the difference of mean thyroid volume was not significant between hilly region and Terai region. Migration of the individuals within the country and more effective supplementary iodine in the hilly and Terai region may be the factors responsible for this difference.

\section{Thyroid volume and Body surface area}

In our study, thyroid volume was best correlated with body surface area $(r=0.444, p<0.0001)$. Thyroid volume increased with increasing body surface area. This observation is similar to that obtained by other researchers. ${ }^{15,16,18,22,27-29}$ In the study performed by Irene Kaloumenou et al, total thyroid volume significantly correlated with BSA in boys $(r=0.730$, $\mathrm{p}<0.0005)$ and girls $(\mathrm{r}=0.623, \mathrm{p}<0.0005) .{ }^{28}$ In another study done by Chanoine JP et al, the volume was best correlated with body surface area $(\mathrm{p}<0.01) .{ }^{16}$ Narseta Mickuvienë et al also found body surface area as the best indicator of thyroid volume assessment and recommended using the criteria based on body surface area in order to evaluate the constitutional characteristics of individual child's development. ${ }^{30}$ Similar observations were made by Svensson J et al. ${ }^{29}$

\section{Thyroid volume and height}

We found significant positive correlation between total thyroid volume and height of the individual $(\mathrm{r}=0.320, \mathrm{p}<$ $0.0001)$. This observation is similar to the study done by Ivanac $\mathrm{G}$ et al. ${ }^{15}$ In their study, thyroid volume was best correlated with body height $(\mathrm{r}=0.37 ; \mathrm{p}=0.001)$.

\section{Thyroid volume and weight}

In our study, thyroid volume was best correlated wtih weight of the individual after body surface area $(r=0.443, p<0.0001)$. This finding is in consistent with the findings of Hegedus $\mathrm{L}$ et $\mathrm{al}^{10}$ Ramazan Sari et $\mathrm{al}^{31}$ and Svensson $\mathrm{J}$ et $\mathrm{al}^{29}$. In the study done by Hegedus L et al, the difference in total thyroid volume between males and females was solely explained by weight. ${ }^{10}$ There was a positive correlation between the changes of thyroid volume and the change of body weight $(r=0 \cdot 341, p=0 \cdot 009)$ in the study done by Ramazan Sari et $\mathrm{al}^{31}$

\section{Thyroid volume and Body Mass Index (BMI)}

We found significant positive correlation of total thyroid volume with body mass index $(r=0.371, p<0.0001)$. This observation is similar to that found by Ramazan Sari et al. ${ }^{31}$ In their study, there was positive correlation of total thyroid volume with BMI $(r=0 \cdot 504, p<0 \cdot 001)$. However, our observation is in contrast to that by Irene Kaloumenou et al who found minimal correlation of total thyroid volume with $\operatorname{BMI}(\mathrm{r}=0.166, \mathrm{p}=0.023) .{ }^{28}$

\section{Conclusions}

This study estimated the age specific reference values for thyroid volume in Nepalese population which will be useful in the clinical practice especially for the diagnosis of goiter. 
The estimated mean thyroid volume in our population is seen to be significantly lower compared to the thyroid volume in the western population showed by different studies done in the west and other different countries.

Thyroid volume best correlated with Body surface area followed by weight and body mass index. Thus body surface area specific reference values would be the best reference values for the use in clinical practice for evaluation of thyroid volume.

Significant difference in thyroid volume is found between the individuals from different geographic region of the country with highest values seen in population of the Himalayan region.

\section{Limitations of our study:}

1. Small sample size

2. Disproportionate demographic representation

3. Disproportionate age representation

4. Other accurate modalities for volume estimation like radionuclide and $3 \mathrm{D}$ ultrasound were not considered in our study

\section{References}

1. Rumack CM, Wilson SR, Charboneau WJ. Diagnostic ultrasound. 3rd ed. vol 1. Elsevier Mosby; p. 735-65.

2. Hegedüs L. Thyroid size determined by ultrasound. Influence of physiological factors and non-thyroidal disease. Dan Med Bull 1990;37:249-63.

3. Knudsen N, Laurberg P, Perrild H, Bülow I, Ovesen L, Jørgensen T. Risk factors for goiter and thyroid nodules. Thyroid. 2002 Oct;12(10):879-88.

4. Miccoli P, Berti P, Materazzi G, et al. Minimally invasive video-assisted thyroidectomy: five years of experience. J Am Coll Surg 2004; 199:243-48.

5. Gagner M, Inabnet WB 3rd. Endoscopic thyroidectomy for solitary thyroid nodules. Thyroid. $2001 \mathrm{Feb} ; 11(2): 161-3$.

6. Daniels GH. Physical examination of the thyroid gland. In: Braverman LE, Utiger RD, editors. Werner and Ingbar's The thyroid: A fundamental and clinical text. 6th ed. Philadelphia, PA: JB Lippincott Co; 1991. p. $572-7$.

7. Greenspan FS. Thyroid gland. In: Greenspan FS, Forsham PH, editors. Basic and clinical endocrinology. 3rd ed. Norwalk, CT: Appleton \& Lange; 1991. p. 213 5 .

8. Tonglet R, Bourdoux P, Dramaix M, Hennart P, Ermans
A. Interobserver variation in the assessment of thyroid enlargement: a pitfall in surveys of the prevalence of endemic goitre. Food Nutr Bull 1994;15:64-70.

9. Berghout A, Wiersinga WM, Smits NJ, Touber JL. Determinants of thyroid volume as measured by ultrasonography in healthy adults in a non-iodine deficient area. Clin Endocrinol (Oxf). 1987 Mar;26(3):273-80.

10. Hegedus L, Perrild H, Poulsen LR, et al. The determination of thyroid volume by ultrasound and its relationship to body weight, age, and sex in normal subjects. J Clin Endocrinol Metab. 1983;56:260-3.

11. Rasmussen SN, Hjorth L. Determination of thyroid volume by ultrasonic scanning. J Clin Ultrasound. 1974;2:143-7.

12. Gutekunst R, Smolarek H, Hasenpusch U, et al. Goitre epidemiology: thyroid volume, iodine excretion, thyroglobulin and thyrotropin in Germany and Sweden. Acta Endocrinol (Copenh). 1986;112:494-501.

13. Wachter W, Pickardt CR, Gutekunst R, et al. Use of ultrasonography for goiter assessment in IDD: studies in Tanzania. In: Hetzel BS, Dunn JT, Stanbury JB, editors. The prevention and control of iodine deficiency disorders. Amsterdam: Elsevier; 1987. p. 95-108.

14. Gutekunst R. The value and application of Ultrasonography in goiter survey. IDD Newslett. 1990;6:3-5.

15. Ivanac G, Rozman B, Skreb F, et al. Ultrasonographic measurement of the thyroid volume, Coll Antropol. 2004;28(1):287-91.

16. Chanoine JP, Toppet V, Lagasse R, et al. Determination of thyroid volume by ultrasound from the neonatal period to late adolescence. Eur J Pediatr. 1991 Apr;150(6):395-9.

17. Perry RJ, Hollman AS, Wood AM, Donaldson MD. Ultrasound of the thyroid gland in the newborn: normative data. Arch Dis Child Fetal Neonatal Ed. 2002 Nov;87(3):F209-11.

18. González M, González CP, Sanabria A. Ultrasonographic estimation of the normal volume of the thyroid gland in pediatric populations. Biomedica. 2006 Mar;26(1):95-100.

19. Dvoráková M, Bílek R, Cerovská J, Hill M, Novák Z, Vavrejnová $\mathrm{V}$, et al. The volumes of the thyroid gland 
in adults aged 18-65 years in the Czech Republicdetermination of the norms, Vnitr Lek. 2006 Jan;52(1):57-63.

20. Zhou J, Huang X, Zhu W, et al. Study on the upper limit and its revision method of normal thyroid volume of children of 8-10 years-old in Zhejiang Province. Wei Sheng Yan Jiu. 2007 Jul;36(4):517-9.

21. WHO/ICCIDD. Recommended normative values for thyroid volume in children age $6-15$ years. Bulletin of the World Health Organization 1997;75:95-7.

22. Xu F, Sullivan K, Houston R, Zhao J, May W, Maberly G. Thyroid volumes in US and Bangladeshi schoolchildren: comparison with European schoolchildren. Eur J Endocrinol. 1999 Jun;140(6):498504.

23. Gutekunst R, Martin-Teichert H. Requirement for goiter surveys and the determination of thyroid size. In: Delange F, Dunn JT, Glinoer D, editors. Iodine deficiency in Europe. New York: Plenum Press; 1993. p. 109-15.

24. Vitti P, Martino E, Aghini-Lombardi F, Rago T, Antonangeli L, Maccherina D, et al. Thyroid volume measurement by ultrasound in children as a tool for the assessment of mild iodine deficiency. Journal of Clinical Endocrinology and Metabolism 1994;79:6003.

25. Ivarsson SA, Persson PH, Ericsson UB. Thyroid gland volume as measured by ultrasonography in healthy children and adolescents in a non-iodine deficient area. Acta Paediatrica Scandinavica 1989;78:633-4.

26. Ueda D. Normal volume of the thyroid gland in children. Journal of Clinical Ultrasound 1990;18:45562.

27. Mickuvienë N, KrasauskienëA, Kazanavièius G. The results of thyroid ultrasound examination in randomly selected schoolchildren. Medicina (Kaunas) 2006;42(9):751-8.

28. Kaloumenou I, Alevizaki M, Ladopoulos C, Antoniou A, Duntas LH, Mastorakos G, et al. Thyroid volume and echostructure in schoolchildren living in an iodine-replete area: relation to age, pubertal stage, and body mass index. Thyroid. 2007 Sep;17(9):875-81.

29. Svensson J, Nilsson PE, Olsson C, Nilsson JA, Lindberg B, Ivarsson SA. Interpretation of normative thyroid volumes in children and adolescents: is there a need for a multivariate model? Thyroid. 2004
Jul;14(7):536-43.

30. Mickuvienë N, Krasauskienë A, Kazanavièius G. The results of thyroid ultrasound examination in randomly selected schoolchildren. Medicina (Kaunas) 2006;42(9):751-8.

31. Sari R, Balci MK, Altunbas H, Karayalcin U. The effect of body weight and weight loss on thyroid volume and function in obese women. Clin Endocrinol (Oxf). 2003 Aug;59(2):258-62. 